\title{
Cigarro Eletrónico: Posição da Sociedade Portuguesa de Pneumologia
}

\author{
Electronic Cigarette: Position of the Portuguese Society of Pneumology
}

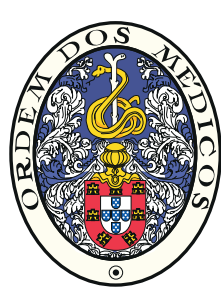

José M. REIS FERREIRA四1,2, Ana FIGUEIREDO ${ }^{3}$, José Pedro BOLÉO-TOMÉ ${ }^{4}$, Carlos ROBALO CORDEIRO ${ }^{5}$

Acta Med Port 2015 Sep-Oct;28(5):548-550

Palavras-Chave: Cessação Tabágica/métodos; Cigarros Electrónicos/efeitos adversos; Nicotina; Portugal.

Keywords: Electronic Cigarettes/adverse effects; Nicotine; Portugal; Smoking Cessation/methods.

\section{INTRODUÇÃO}

Os dispositivos eletrónicos de dispensa de nicotina, também conhecidos pela sigla ENDS (Electronic Nicotine Delivery Systems), vulgarmente designados por cigarros eletrónicos ou e-cig, têm vindo a alcançar assinalável êxito comercial de vendas em muitos países, em torno do globo. Surgindo numa época em que se desenhava um end game para o fumo do tabaco, com amplas iniciativas para limitar o seu uso em locais públicos e para desincentivar o início desse hábito entre não fumadores, sobretudo entre os jovens, o cigarro eletrónico surge como um risco e um isco: risco de 'renormalização' do hábito de fumar, inclusive em público e em locais fechados, e um isco para os que anseiam por novos comportamentos, que procuram a moda, estando disponíveis para novos apelos do marketing e do design.

Estes dispositivos têm, na sua origem, a procura dum método aceitável e eficaz para os fumadores que querem deixar de fumar, um novo método de cessação tabágica, mas os seus mais recentes desenvolvimentos e campanhas comerciais estão muito mais orientados para a captação, satisfação e fidelização de novos clientes.

Já não se fala de fumar tabaco, processo que envolve a combustão das respetivas folhas, devidamente preparadas e previamente acondicionadas; origina-se assim grande quantidade de produtos nocivos, por vezes irritantes para a respiração e que deixam cheiro e depósito desagradáveis. Agora o ritual consiste em vapear, aspirar um aerossol com base em água, sem combustão, produzido por um pequeno dispositivo eletrónico de vaporização, o qual transporta nicotina em quantidade mais ou menos padronizada, acompanhada de sabores ou de aromas diversos, colocados à escolha do utilizador e de muitas outras substâncias, nem todas descritas ou identificadas.

Pretende-se assim dispensar em cada inalação um vapor 'limpo' de substâncias adversas e desnecessárias, eventualmente prejudiciais à saúde.

Para além disso, cria-se à volta do ato de vapear uma certa aura de encanto, de elegância e de adequação a novas necessidades da vida quotidiana, bem servidas pelas mais recentes tecnologias, por exemplo, ligando o vapear à audição de música (controlo do volume do áudio no próprio dispositivo eletrónico, ou ligação às mais variadas funções do telefone portátil inteligente).

Tudo isto por preços módicos, mais baratos que os dos cigarros convencionais, sendo possível recarregar a bateria do dispositivo através da porta do computador portátil e pretendendo alcançar efeitos calmantes para o sistema nervoso, com benefícios para a cessação ou controlo do consumo exagerado de tabaco.

A evidência científica e clínica quanto às potencialidades destes dispositivos no campo da saúde humana ainda são, todavia, insuficientes e tendem a ser fortemente enviesadas pelos interesses envolvidos neste setor comercial.

\section{ATITUDE DA COMUNIDADE CIENTÍFICA FACE AO ÊXITO DOS ENDS}

A posição das Sociedades Médicas quanto ao fenómeno dos dispositivos eletrónicos de dispensa de nicotina tem sido hesitante e cautelosa, devido à escassa consistência dos resultados deste novo hábito, que muitos receberam tacitamente como os de um 'mal menor', face aos bem conhecidos danos provocados pelo fumo do tabaco.

A Sociedade Torácica Americana apela a mais e melhor investigação, e à informação plena e imparcial do público e das entidades decisoras e políticas, recorrendo para tal à ajuda dos reguladores oficiais (Food and Drug Administration (FDA)). ${ }^{1}$

Por outro lado, a Organização Mundial da Saúde (OMS) tem desenvolvido esforços para condensar a investigação disponível relativa ao impacto na saúde dos cigarros

1. Editor. Boletim "Oxigénio". Sociedade Portuguesa de Pneumologia. Lisboa. Portugal.

2. Comissão de Trabalho de Tabagismo. Sociedade Portuguesa de Pneumologia. Lisboa. Portugal.

3. Coordenadora. Comissão de Trabalho de Tabagismo. Sociedade Portuguesa de Pneumologia. Lisboa. Portugal.

4. Secretário. Comissão de Trabalho de Tabagismo. Sociedade Portuguesa de Pneumologia. Lisboa. Portugal.

5. Presidente. Sociedade Portuguesa de Pneumologia. Lisboa. Portugal.

$\triangle$ Autor correspondente: José M. Reis Ferreira. reis0ferreira@gmail.com

Recebido: 22 de Dezembro de 2014 - Aceite: 29 de Dezembro de 2014 | Copyright @ Ordem dos Médicos 2015 
eletrónicos, mostrando preocupação relativamente à extensa publicidade que os envolve, nomeadamente naquilo que respeita a jovens e não fumadores. ${ }^{2}$

Várias sociedades e organizações de profissionais de saúde têm tomado posição sobre o assunto, em regra recomendando cautela relacionada com a insuficiente evidência científica e também com variadas situações em que o seu uso tanto pode ser útil como arriscado e prejudicial. ${ }^{3}$

O benefício potencial destes dispositivos na redução de riscos em relação aos cigarros convencionais foi extensamente revista em recente avaliação de 76 estudos disponíveis, mas ainda não se afigura possível admitir conclusões satisfatórias, porque estes estudos estão frequentemente contaminados por conflitos de interesses. ${ }^{4}$

O próprio uso de cigarros eletrónicos para doentes com cancro, como uma redução do risco relativamente ao tabaco, não é recomendável por parte dos clínicos, por escassez de evidência que o suporte. ${ }^{5}$

Por outro lado, levantam-se sérias reservas relacionadas com a implicação da nicotina como facilitadora da mutação de células, danificadora do genoma, disruptiva de processos metabólicos celulares, amplificadora de oncogenes, inativadora de genes supressores dos tumores e promotora de um microambiente propiciador do cancro, o que é recentemente afirmado num artigo de perspetiva da revista Nature. ${ }^{6}$

Tabela 1 - Atitude sugerida em casos tipo

Situação do Utente

O fumador conseguiu já cessar de fumar e não coloca a questão de utilizar cigarro eletrónico

O fumador conseguiu cessar de fumar e coloca a questão de utilizar cigarro eletrónico

O fumador está motivado mas não conseguiu cessar de fumar e coloca esperança no uso de cigarro eletrónico

O fumador, apesar de razoável motivação não conseguiu cessar de fumar mas pergunta qual o método a seguir para conseguir

O fumador não está motivado para cessar, mas admite usar o cigarro eletrónico como redução do risco do tabaco

O fumador afirma-se convicto de continuar a fumar e pergunta se pode usar o cigarro eletrónico como um apoio para locais onde não pode fumar

\section{POSIÇÃO ACERCA DO CIGARRO ELETRÓNICO}

A comercialização livre de cigarros eletrónicos coloca evidentes reservas, pelo modo exponencial como se vem afirmando em todo o mundo, em diversas classes de público.

À Sociedade Médica em geral preocupa sobretudo o seu impacto nos jovens, em não fumadores atuais e ainda em certos grupos de risco, onde o cigarro eletrónico pode surgir como um contorno à possibilidade da cessação, como as grávidas.

É igualmente preocupante a associação deste hábito à moda ou ao fascínio pela inovação e pelo progresso, porque renormaliza na sociedade o gesto e ritual de fumar. ${ }^{7}$

A possibilidade do uso 'desculpabilizado' de nicotina poder ter um efeito de portal de entrada para a habituação ao tabaco ou a outros produtos causadores de dependência é também uma séria preocupação a considerar pela comunidade dos profissionais de saúde. Este risco tem sido fundamentado recentemente em investigação translacional bem alicerçada. ${ }^{8}$

Estes conhecimentos devem determinar normas reguladoras do mercado, que minimizem os danos futuros. As agências estatais de regulação têm de tomar uma posição clara neste sentido. ${ }^{9} \mathrm{Em}$ Portugal, esta regulação pública tarda, sendo urgente que venha a ser discutida e implementada.
Atitude do Profissional de Saúde

Congratular pelo êxito e reforçar os benefícios a esperar da cessação e a necessidade de estar alerta para "deslizes", contrariando o excesso de confiança

Dar os parabéns pelo êxito conseguido, convidar a mudar as rotinas e tentar conseguir mais bem estar no dia a dia

Salientar as vantagens em cessar e apelar à prioridade em atingir cessação completa de tabaco

Tentar avolumar a evidência das vantagens e urgência em cessar com êxito, escolher os métodos que melhor podem ser aceites e resultarem no caso concreto

Afirmar e demonstrar os benefícios de cessar de fumar, mostrar disponibilidade para discutir estas questões

Aconselhar proactivamente a cessação, como um processo terapêutico e preventivo necessário - informar o mais amplamente possível e com evidências claras

\section{Posição quanto ao Cigarro Eletrónico}

Em caso de êxito não recomendar e até precaver contra o uso de cigarro eletrónico, por risco de facilitar a reaproximação ao ritual de fumar e de recaída

Em caso do cigarro eletrónico estar a resultar, lembrar a importância de marcar uma data de cessação para o uso desses dispositivos, lembrando alternativas mais seguras e o risco de recaída no tabaco

Lembrar que o cigarro eletrónico pode ser uma ilusão e um subterfúgio para não cessar, que será sempre uma solução parcial e arriscada para a saúde

Abordar os métodos de cessação convencionais sem incluir o cigarro eletrónico e, caso haja questões sobre estes dispositivos, insistir em que o cigarro eletrónico não demonstrou ainda ser um método adequado de cessação.

Esclarecer que os cigarros eletrónicos têm riscos para a saúde que lhe são próprios, não são inofensivos e nem sempre resultam em reduzir o consumo de tabaco

Desincentivar o uso de cigarros eletrónicos em locais fechados, pelos riscos que envolve para outros e pela falta de provas da sua segurança para o consumidor 
Poderá ser admitido o uso do cigarro eletrónico na cessação?

Não há dados científicos suficientes para recomendar o cigarro eletrónico na cessação tabágica. Neste item as opiniões dos clínicos e investigadores dividem-se, mas o conhecimento é insuficiente e a OMS afirma ser esta uma solução insegura, não sendo sustentado o sucesso da cessação, a não ser que o fumador escolha pessoalmente esta via e se comprometa, em prazo definido, a acabar também com o uso de cigarros eletrónicos. ${ }^{2}$

Nas conclusões da recente Conferência para o Controlo do Tabaco, a OMS reitera que a indicação para a cessação só pode ser aceite se houver confirmação da segurança e eficácia dos produtos e dispositivos pelas Autoridades Reguladoras da Saúde, e que esta indicação clínica não deve ser aceite como veículo comercial. ${ }^{10}$

A Sociedade Portuguesa de Pneumologia, através da Comissão de Trabalho de Tabagismo, alerta a comunidade médica a não recomendar aos seus doentes o uso complacente de cigarros ou de dispositivos eletrónicos de dispensa de nicotina (Tabela 1). Ainda que estes possam ser escolhidos pelos utentes e doentes, como uma opção individual, esta não deve ser corroborada pelos profissionais de saúde, com base nos atuais conhecimentos e evidência científica. Por outro lado, existem fármacos com eficácia e segurança na cessação tabágica bem conhecidas, através de estudos controlados, cujo uso por profissionais habilitados constitui a nossa recomendação.

A hipótese de o cigarro eletrónico constituir uma redu-

\section{REFERÊNCIAS}

1. Brody JS. The promise and problems of e-cigarettes. Am J Respir Crit Care Med. 2014;4:379-89.

2. Grana R, Benowitz N, Glantz SA. E-cigarettes: a scientific review. Circulation. 2014;129:1972-86

3. Schraufnagel DE, Blasi F, Drummond MB, Lam DC, Latif E, Rosen MJ, et al. A position statement of the Forum of International Respiratory Societies. Am J Respir Crit Care Med. 2014;6:611-8.

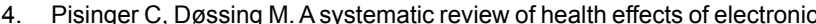
cigarettes. Prev Med. 2014;69:248-60.

5. Cummings KM, Dresler CM, Field JK, Fox J, Gritz ER, Hanna NH, et al. E-cigarettes and cancer patients. J Thorac Oncol. 2014;9:438-41.

6. Grando SA. Connections of nicotine to cancer. Nat Rev Cancer. ção de riscos relativamente ao tabaco é altamente contestada e, embora se admita que seja real em alguns casos, não é de modo nenhum a regra, não devendo assumir-se como verdade nem fundamento de recomendação clínica.

Alertamos ainda as autoridades reguladoras para que atuem de forma decidida em regulamentar a venda e promoção do cigarro eletrónico, proibindo a sua promoção entre jovens. Recomendamos ainda a proibição da publicidade a estes dispositivos e do seu uso em locais fechados, ou onde estes produtos possam atingir outas pessoas, nomeadamente grupos de pessoas suscetíveis e frágeis aos seus efeitos, como crianças e doentes crónicos.

Foram necessárias décadas, desde que se estabeleceram relações causais claras entre o fumo do tabaco e múltiplas doenças, até ao início do seu controlo e proibição. É urgente que não se espere demasiado tempo para regulamentar ou até proibir o cigarro eletrónico até que existam estudos conclusivos de longa duração, porque as consequências para a saúde das pessoas poderão já ter sido profundamente negativas.

\section{CONFLITOS DE INTERESSE}

Os autores são Membros ativos da Sociedade Portuguesa de Pneumologia e integram a Comissão de Trabalho de Tabagismo desta Sociedade Médica Científica.

\section{FONTES DE FINANCIAMENTO}

Este trabalho não recebeu nenhuma contribuição de subsídio ou bolsa.

2014;14:419-29

7. Knorst MM, Benedetto IG, Hoffmeister MC, Gazzana MB. Cigarro eletrônico: o novo cigarro do século 21? J Bras Pneumol. 2014;40:56473.

8. Kandel ER, Kandel D. A molecular basis for nicotine as a gateway drug N Eng J Med. 2014;371:932-43.

9. Cobb NK, Abrams DB. The FDA, e-cigarettes, and the demise of combusted tobacco. N Eng J Med. 2014;371,16:1469-71.

10. Sixth session of the Conference of the Parties to the WHO FCTC; [consultado 2014 nov 30]. Disponível em http://www.who.int/fctc/cop/ sessions/cop6/en 


\section{Cigarro Eletrónico: Posição da Sociedade Portuguesa de Pneumologia}

Acta Med Port 2015:28:548-550

Publicado pela Acta Médica Portuguesa, a Revista Científica da Ordem dos Médicos

Av. Almirante Gago Coutinho, 151

1749-084 Lisboa, Portugal.

Tel: +351218428215

E-mail: submissao@actamedicaportuguesa.com

www.actamedicaportuguesa.com

ISSN:0870-399X | e-ISSN: 1646-0758

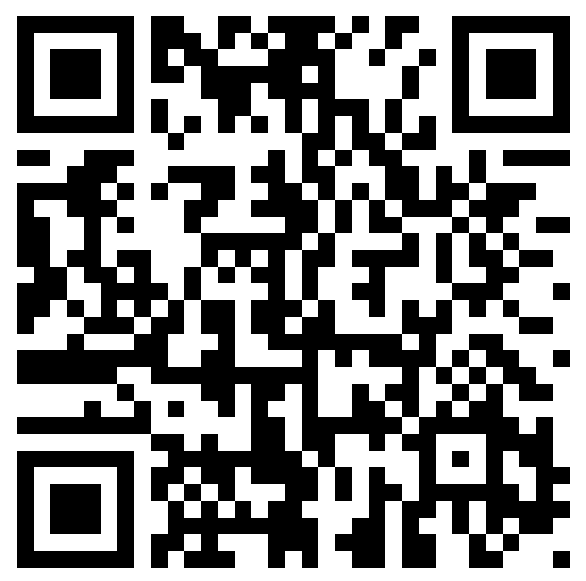

